\title{
¿PODRÁN CORTAR TODAS LAS FLORES? LA DIMENSIÓN DE "NORMALIDAD" EN LA VIDA PÚBLICA DE LAS INSTITUCIONES JUDÍAS DURANTE LA ÚLTIMA DICTADURA MILITAR ARGENTINA (1976-1983)
}

\author{
EMMANUEL N. KAHAN (IdIHCS-CONICET / NEJ-IDES) \\ emmanuel.kahan@gmail.com
}

\begin{abstract}
Resumen:
Las nociones de "normalidad" y "florecimiento" se transformaron en un tópico central de las interpretaciones en torno de la actitud de la dirigencia de la "comunidad judía argentina" durante la dictadura militar. Más para impugnar las prácticas de quienes estuvieron al frente de las instituciones centrales que para indagar en torno de qué significó que la "vida judía" estuviera signada por patrones de "normalidad" y "florecimiento".

Pero ¿por qué debería sorprendernos las categorías de "florecimiento" y/o "normalidad" del funcionamiento de la vida institucional judía durante el contexto dictatorial? ¿Acaso sería correcto señalar los registros de vida "normalizada" en un contexto signado por el estado de excepción? Si los estudios sobre la dictadura se han centrado en explicar el carácter represivo del régimen, no sería un problema menor comprender cómo es que un actor -supuestamente sensible a la implementación de las políticas persecutorias- pudo desarrollar una vida pública sin sentirse amenazado.

El presente trabajo intentará establecer de qué se trató el "florecimiento" y la "normalidad" de la vida institucional en dictadura, problematizando cómo algunos espacios actuaron como subterfugios de las prácticas políticas, culturales y sociales que contrastaron con el modelo cultural sostenido por el régimen militar. Pero a su vez, permitirá poner en escena un problema que tampoco puede ser considerado menor: el registro de la diversidad de temas frente a los cuales debieron posicionarse los actores - no sin enfrentamientos, en muchas oportunidadesevidenciará que estos no fueron interpelados solamente por los temas de la agenda "política nacional". Lo que podría denominarse la "agenda institucional y/o judía", concentró en muchas oportunidades su atención.
\end{abstract}

\section{Palabras Clave:}

Judíos - Dictadura - Vida Cotidiana - Argentina

\begin{abstract}
:
The notions of "normality" and "blooming" became a central topic of interpretations about the attitude of the "Jewish community's leadership" during the military dictatorship. These concepts were used more to contest the practices of those who were at the head of the central institutions, than by a will to understand the meaning that these patterns of "normality" and "blooming" actually had for "Jewish life".

But, why should this presence of the concepts of "blooming" and/or "normality" in the daily functioning of Jewish institutional life within the dictatorial context be surprising at all? Would it be right to focus on the "normalized" aspects of life precisely within context defined by a state of exception? Given the fact that most studies about the military dictatorship have focused on the repressive dimension of the regime, it would not be a minor issue to reach an understanding of how a social agent allegedly sensitive to implementation of persecutory policies, could develop a rich public life without feeling particularly threatened.

This paper will attempt to establish what these notions of "normality" and "blooming" actually meant for Jewish institutional life during the dictatorship, and to identify some spaces that acted
\end{abstract}


as subterfuges, of political, cultural and social practices which contrasted with the cultural model supported by the military regime. But it will also attempt to shed some light on a problem that cannot be understated: the acknowledgment of the diversity of issues that the main institutional agents had to take side on -many times not without internal struggle-, showing that they were not solely influenced by the agenda of the "national political sphere", but also by what could be defined as the "institutional" or "Jewish agenda", to which the main actors devoted in many cases most of their attention.

\section{Keywords:}

Jews - Dictatorship - Daily Life - Argentina 


\section{¿PODRÁN CORTAR TODAS LAS FLORES? LA DIMENSIÓN DE "NORMALIDAD" EN LA VIDA PÚBLICA DE LAS INSTITUCIONES JUDÍAS DURANTE LA ÚLTIMA DICTADURA MILITAR ARGENTINA (1976-1983)}

EMMANUEL N. KAHAN (IdIHCS-CONICET / NEJ-IDES)

emmanuel.kahan@gmail.com

\section{Presentación}

Como se abordará en el primer apartado de esta trabajo, los dirigentes de la Delegación de Asociaciones Israelitas de Argentina (DAIA) señalaron que entre los objetivos prioritarios de la entidad durante el período dictatorial se encontraba el sostenimiento de la "especificidad institucional" de la "comunidad judía" argentina. En oposición a lo que habían sido los días aciagos del tercer gobierno peronista, la propuesta de mantener la "normalidad" de la vida institucional no se trataba de un tópico menor. No obstante, como señalarían los mismos dirigentes en polémicas posteriores - cuando en los primeros tramos de la transición democrática sean acusados por no haber hecho nada ante la "detención-desaparición de individuos de origen judío"- el período dictatorial estuvo signado por el "florecimiento" de la vida institucional.

Las nociones de "normalidad" y "florecimiento" se transformaron, desde entonces, en un tópico central de las interpretaciones en torno de la actitud de la dirigencia de la "comunidad judía" durante la dictadura militar. Más para impugnar las prácticas de quienes estuvieron al frente de las instituciones centrales que para indagar en torno de qué significó que la "vida judía" estuviera signada por patrones de "normalidad" y "florecimiento". Pero, ¿por qué debería sorprendernos las categorías de "florecimiento" y/o "normalidad" del funcionamiento de la vida institucional judía durante el contexto dictatorial? ¿Acaso sería correcto señalar los registros de vida "normalizada" en un contexto signado por el estado de excepción?

Si los estudios sobre la dictadura se han centrado en explicar el carácter represivo del régimen, no sería un problema menor comprender cómo es que un actor- supuestamente sensible a la implementación de las políticas persecutorias ${ }^{2}$ - pudo desarrollar una vida pública sin sentirse

\footnotetext{
1 Si bien la investigación social reconoce la heterogeneidad de los "judío" ésta asume frecuentemente que los "judíos”, más allá de cualquier conflicto y diferencia, conforma prioritariamente una comunidad. El problema es que el concepto de comunidad -al menos aplicado a lo "judío"- se caracteriza por su polisemia. En este sentido, propone Marcelo Dimenstein, quizás sea preciso tomar la noción, siguiendo el consejo de los antropólogos, como una categoría nativa. Es por esto que para el desarrollo de este trabajo se optó por consignar entre-comillas la expresión nativa de "comunidad judía". Ver Dimenstein, M., "Algunas reflexiones sobre el uso del término 'comunidad' para referirse a los judíos", ponencia presentada en "Encuentro de intelectuales jóvenes judíos”, Asociación Mutual Israelita de Argentina, agosto de 2006.

${ }^{2}$ La bibliografía acerca de la "comunidad judía" durante la dictadura militar enfatizó el rasgo antisemita del régimen. Ver: Klich, I., "Política comunitaria durante las Juntas Militares argentinas: La DAIA durante el Proceso de Reorganización Nacional", en Senkman, Leonardo (comp.), El antisemitismo en Argentina., Centro Editor de América Latina, Buenos Aires, 1986; Zohar, M., Manda a mi pueblo al Diablo, Tel Aviv, Zitrin, 1990 [en hebreo]; Lotersztain, G., Los judios bajo el terror, Buenos Aires, Ejercitar la Memoria, 2008; Lipis, G., Zikaron-Memoria. Los judíos bajo el Plan Cóndor., Buenos Aires, Del Nuevo Extremo, 2010; Dobry, H., Los judios y la dictadura., Buenos Aires, Vergara, 2013.
} 
amenazado. Quizás, incluso, ayude a comprender por qué para la dirigencia judía no constituyó la desaparición de "individuos de origen judío" un tema central o por qué ni siquiera afectó la dinámica de la vida institucional. Pues, en contraste con las tensiones que caracterizaron la "vida judía" en durante el tercer gobierno peronista ${ }^{3}$, la vida institucional durante el período dictatorial "floreció" de forma tal como no había registro en la memoria próxima de los actores.

El presente trabajo intentará establecer de qué se trató el "florecimiento" y la "normalidad" de la vida institucional en dictadura problematizando cómo algunos espacios actuaron como resguardo de las prácticas políticas, culturales y sociales que contrastaron con el modelo cultural sostenido por el régimen militar. La propuesta no es en menoscabo- ni desconoce- aquellas investigaciones que señalan el rasgo más sobresaliente del período dictatorial: el terrorismo de Estado y la práctica de la desaparición forzada de personas. Pero reconociendo el debate sostenido por Martin Broszat y Saúl Friëdlander acerca de cómo abordar el pasado nazi en Alemania, este artículo retoma las consideraciones del primero acerca de la posibilidad de comprender que más allá de los registros de barbarie y horror de nazismo, existieron patrones de "vida normalizada".

Para poder relevar este objetivo fue necesario abordar un objeto de estudio constituido por diversos actores. ¿Cómo ordenar en un relato coherente esa multiplicidad de voces que, en determinadas circunstancias y frente a problemas particulares, se expresaron al unísono aunque no unívocamente? La investigación optó por construir una narrativa que pudiera indagar acerca de cómo se constituyó, cuáles fueron las tensiones y qué posicionamientos se fraguaron en el espacio público "judío" durante la última dictadura militar. Si bien, el investigador -como los lectores- no podría desconocer las jerarquías que detentan algunas de las instituciones "judías" en el espacio público - por ejemplo, la centralidad de la Delegación de Asociaciones Israelitas de Argentina (DAIA)-, la investigación optó por recuperar otros actores que intervinieron -incluso, aquellos menos reconocidos-, pero que en determinadas situaciones dieron sentido a un conjunto de prácticas extendidas y gravitantes dentro de la "comunidad judía".

De esta forma, junto a las reconocidas DAIA y AMIA, se encontrará el Idisher Cultur Farband o Federación de Entidades Culturales Israelitas (ICUF), la Sociedad Hebraica Argentina (SHA), la Confederación Juvenil Judeo Argentina (CJJA) y la Organización Sionista Argentina (OSA). A su vez, serán analizados los actores a través de los posicionamientos registrados en la prensa "comunitaria": Mundo Israelita , La Lu₹ y Nueva Presencia?.

\footnotetext{
3 Senkman, Leonardo, "El antisemitismo bajo dos experiencias democráticas: Argentina 1959-1966 y 1973-1976", en Senkman, Leonardo (comp.), El antisemitismo en Argentina, op. cit., pp. 109-187; Kahan, E., "Entre Cámpora, Perón y Pinochet: la radicalización del discurso de las organizaciones judías argentinas.", en Judaica Latinoamericana, Vol. 6, 2013, págs. 487-510.

4 Para el debate entre Martin Broszat y Saúl Friëdlander véase Kershaw, Ian. "Normalidad y genocidio: el problema de la "historización" en La dictadura nazi. Problemas y perspectivas de interpretación, Buenos Aires, Siglo XXI, 2004, pp. 287-308.

${ }^{5}$ Periódico cuyo origen se remonta a 1923 y que se convirtió en la publicación judía más leída en castellano. Sus posiciones estuvieron próximas a las conducciones de las instituciones centrales de la "comunidad judía". Véase Dujovne, Alejandro, "Cartografía de las publicaciones periódicas judías de izquierda en Argentina, 1900-1953" en Revista del Museo de Antropología No 1, Facultad de Filosofía y Humanidades, Universidad Nacional de Córdoba, 2008, pp. 121-138.

6 Publicación semanal ligada a la sección local del partido político sionista revisionista Jerut, considerado popularmente de "derecha".

${ }_{7}^{7}$ Sección en castellano del periódico idishista Di Presse. Para una historia de Nueva Presencia, ver: Kahan, Emmanuel, "La construcción de íconos en torno a la resistencia dictatorial. El semanario Nueva Presencia y la resistencia a la dictadura militar en Argentina, 1977-1983”, en Barreneche, Osvaldo y Bisso, Andrés, El tiempo pasa, la historia queda. Ayer, hoy y mañana son contemporáneos, La Plata, Universidad Nacional de La Plata, 2010.
} 


\section{“El reino del revés": la actividad política, la participación y los debates}

Novaro y Palermo señalan que entre las estrategias de la dictadura militar para obturar toda posible oposición al régimen, este suprimió celosamente el uso del espacio público. Entendiéndolo como un espacio al alcance de todos, de libre circulación de voces y discursos y de libre vinculación y contienda entre los actores, el régimen consiguió que dejara de existir por varios años de forma inédita. ${ }^{8}$ Según los autores, el régimen no estuvo dispuesto a permitir ninguna acción que pudiera reconstruir dicho espacio público, donde emergieran voces desafiantes con discursos críticos, o articulaciones entre grupos o actores sociales, ni siquiera iniciativas culturales que pudieran dar lugar a aventuras estéticas autónomas: "Como sucedía con la propia vida familiar, sino se acomodaba a los moldes establecidos, cualquiera de esas manifestaciones sería considerada "política" y tratada, en consecuencia, como una amenaza al orden".

Sin embargo, el relevamiento de las fuentes documentales de la "comunidad judía" registra diversas anomalias que invitan complejizar la dimensión del espacio público durante el régimen dictatorial. Se podría proponer, a modo de primera hipótesis, que la esfera pública se caracterizó por una serie de múltiples intervenciones que pudieron continuar funcionando en la medida que no pusieran en cuestión el objetivo legitimador del régimen dictatorial: la "lucha contra la subversión".

A poco más de un mes de ocurrido el golpe militar, por ejemplo, el ICUF convocaba al "primer acto público" autorizado por la Junta Militar: el de recordación del "Levantamiento del Ghetto de Varsovia". La cita, en el Cine Majestic el 25 de abril de 1976, se efectuó bajo el siguiente lema nada más ni nada menos-:

"Para cerrar el paso a la escalada fascista en América Latina y en la Argentina. / Contra el terrorismo -cualquiera sea su signo- y la amenaza del Golpe de Estado / Contra el antisemitismo y los odios raciales fomentados por el fascismo / Por la paz en Medio Oriente / "Dígale NO al Fascismo. ¡Solidaridad con los pueblos hermanos de Sud América sometidos a su terror! ¡Contra los asesinatos, secuestros y asaltos de las bandas fascistas". ${ }^{10}$

La crónica posterior destacó el amplio número de los concurrentes al "primer acto público de contenido político autorizado en la Capital Federal por las nuevas autoridades nacionales". ${ }^{11}$ Hablaron Berta Drucaroff, presidenta del "Comité 19 de Abril", Eduardo Pimentel, León Ianulewicz (consejero de la Embajada de la República Popular de Polonia) y Rubén Sinay. Para finalizar, el Grupo Argentino de Teatro para Todos (GATT) interpretó fragmentos de la obra "Yo, Bertolt Brecht, digo", que se estaba presentando en el Teatro IFT. ${ }^{12}$

El desarrollo temprano de esta actividad quizás pueda explicarse comprendiendo quiénes fueron sus promotores. El Idisher Cultur Farband (ICUF) constituía una organización cercana, aunque no dependiente, del Partido Comunista Argentino (PCA). La misma fue creada en 1947 y resultó

\footnotetext{
${ }^{8}$ Novaro, Marcos y Palermo, Vicente, La dictadura militar 1977/1983. Del golpe de Estado a la restauración democrática., Buenos Aires, Paidós, 2003, p. 150.

${ }^{9}$ Novaro, Marcos y Palermo, Vicente, La dictadura militar..., op. cit.

10 “Convocatoria Acto de Levantamiento del Ghetto de Varsovia", Tiempo No 88, marzo de 1976. En el ejemplar del mes de abril de Tiempo se encuentra la confirmación del acto: "El gran acto antifascista está autorizado"

11 "El Gran Acto Antifascista", Tiempo N 90, mayo de 1976.

${ }^{12}$ La obra estuvo dirigida por Marcelo Sola y su título completo era "Yo, Bertolt Brecht digo (poemas de exiliados, canciones y datos biográficos". En el mismo teatro se presentaron otras obras con textos de Bertolt Brecht durante la dictadura militar: "El preceptor" (Enrique Laportilla, 1980) y "La buena persona de Sechuan" (Miguel Candella y Horacio Medrano, 1981). Véase Pelletieri, O., De Bertolt Brecht a Ricardo Monti. Teatro en lengua alemana y teatro argentino 1900-1994, Buenos Aires, Galerna, 1994.
} 
heredera de la Ievsetækie, sección idiomática idishista del PCA. ${ }^{13}$ Como sostiene Gabriela Águila en su trabajo acerca del Partido Comunista durante la dictadura militar, los partidos políticos de izquierda sufrieron un trato diferenciado por las autoridades militares. Mientras algunos fueron prohibidos, otros sólo sufrieron restricciones en su accionar público. Este fue el caso del Partido Comunista, que siguió siendo legal y mantuvo su estructura organizativa. En este sentido, la línea sostenida por el Partido Comunista, resultó coincidente con la del editorialista de Tiempo, Grisha Weltman, al caracterizar al nuevo golpe militar de manera distinta al régimen "pinochetista" y distinguiendo, en el plano local, a los sectores "duros" y "blandos" -O "pinochestistas" y "democráticos"- de las Fuerzas Armadas. ${ }^{14}$

Como en el caso del acto convocado por el "Comité 19 de Abril", perteneciente al ICUF, los actos de conmemoración del "Levantamiento del Ghetto de Varsovia" y los de celebración del "Aniversario de la creación del Estado de Israel" se siguieron realizando durante todo el período. Si bien se pudo observar un desplazamiento de los discursos y la efusividad militante que los sectores juveniles habían mostrado durante la primera mitad de la década de los 70', los actos mostraron una masiva concurrencia. ${ }^{15}$

En 1977 se advertía desde Mundo Israelita que el acto recordatorio del "Levantamiento del Ghetto de Varsovia" se había transformado en el evento más significativo de la movilización en el seno de la "comunidad judía" y que, por lo tanto, los organizadores debían tener presente que la sala de la Sociedad Hebraica Argentina (SHA) ya había dado muestras de quedar muy pequeña. ${ }^{16} \mathrm{No}$ obstante, como señaló la crónica posterior, la conmemoración se realizó en el Teatro del SHA y el público, ante una sala colmada, debió quedar de pie en los pasillos o retirarse sin poder asistir al acto. ${ }^{17}$

En 1978, asimismo, durante la celebración del "Aniversario de la Creación del Estado de Israel”, 20.000 personas concurrieron al acto que tuvo lugar en el Luna Park. ${ }^{18}$ La nutrida concurrencia se debió a la algarabía que suscitó entre los actores de la "comunidad judía" el acercamiento entre Israel y un país árabe, Egipto, a finales del año 1977. ${ }^{19}$ El 26 de marzo de 1979, cuando se rubricó el acuerdo de Camp David, una multitud se congregaría frente a la Embajada de Israel en Buenos Aires para ver la firma del acuerdo -que fue transmitida por satélite en los Canales $11 \mathrm{y}$ 13- y celebrar el "paso hacia la paz en Medio Oriente". A posteriori, señala la crónica, las

13 Sobre los judíos en el PCA y sus organizaciones ver: Schenkolewski-Kroll, Silvia, "La conquista de las comunidades: el movimiento sionista y la comunidad ashkenazi de Buenos Aires (1935-1949)", en Judaica Latinoamericana, Estudios Históricos y Sociales II, Jerusalem, Ed. Universitaria Magnes, 1993; Svarch, Ariel, “Comunistas judíos o judíos comunistas? El activismo y la lucha de la rama judía del PC en un contexto de crisis identitaria, 1920-1950", ponencia presentada en las X Jornadas Interescuelas/Departamentos de Historia, Rosario, 2005; Kersffeld, Daniel, "Entre la Torá y El Manifiesto: tensiones en la construcción de la identidad judeocomunista en América Latina", ponencia presentada en la XIV International Research Conference of LAJSA, Universidad de Tel Aviv, Israel, 27 de julio de 2009; Camarero, Hernán, "El mundo obrero judío comunista", en A la conquista de la clase obrera. Los comunistas y el mundo del trabajo en la Argentina, 1920-1935, Buenos Aires, Siglo XXI, 2007; Kersfeld, Daniel, Rusos y rojos. Judíos comunistas en los tiempos de la Comitern, Buenos Aires, Capital Intelectual, 2012.

14 Águila, Gabriela, "El Partido Comunista Argentino entre la dictadura y la transición democrática", en Revista de Historia Actual No 6, Universidad de Cádiz, 2009.

${ }^{15}$ Kahan, Emmanuel, "El conflicto árabe-israeli al calor del proceso de radicalización política argentina (1973-1975)" ponencia presentada en las VII Jornadas de Sociología de la Facultad de Humanidades y Ciencias de la Educación, Universidad Nacional de La Plata, 6 de diciembre de 2012.

16 "Homenaje en nuestro medio a los héroes del Ghetto de Varsovia", Mundo Israelita, 19 de marzo de 1977.

17 "El $34^{\circ}$ aniversario de la rebelión del Ghetto de Varsovia fue recordado por la judeidad argentina", Mundo Israelita, 23 de abril de 1977.

18 "En vibrante manifestación la comunidad festejó el $30^{\circ}$ Aniversario de la Independencia de Israel", Mundo Israelita, 20 de mayo de 1978; "El Luna Park fue totalmente colmado en un memorable 'Saludo a Israel”, La Lu₹, 19 de mayo de 1978.

${ }^{19}$ El 19 de noviembre de 1977, el premier egipcio Anwer Al-Sadat, visitó Israel y asistió al Parlamento de aquel país en un gesto de reconocimiento -el primero realizado por los países árabes- de la legitimidad del Estado israelí. 
instituciones de la "comunidad judía" promovieron todo tipo de actos festivos: los centrales estuvieron en el Templo de la Congregación Israelita de la República Argentina (CIRA) y en la Sociedad Hebraica Argentina. ${ }^{20}$ Un acontecimiento de similar magnitud se registró cuando, en 1980, las entidades centrales de la "comunidad judía" -DAIA, AMIA, OSA y CJJA- organizaron un acto en el Teatro Gran Rex, el domingo 17 de agosto, con la presencia del militar y líder político israelí, Itzjak Rabín. ${ }^{21}$

Incluso, pese a la prohibición que pesaba sobre las actividades políticas, los jóvenes pertenecientes a las agrupaciones sionistas se identificaron con el movimiento pacifista israelí "Shalom Ajshav" (Paz Ahora), creando una filial local en Buenos Aires. ${ }^{22}$ Si bien la militancia de los sectores juveniles se limitó públicamente a reivindicar problemáticas "sionistas", esta también produjo tensiones al interior de la red de instituciones judías. La conformación de una agrupación local emparentada con el movimiento pacifista israelí dio lugar a que actores locales ligados al partido conservador israelí "Likud" levantarán banderas antagónicas: lo que Israel debía encontrar era una "Paz Segura". ${ }^{23}$

Los jóvenes pertenecientes a la filial local de "Paz Ahora" se movilizaron hasta la sede de la redacción de Nueva Presencia, ubicada en la calle Castelli $\mathrm{N}^{\circ} 330$, en la ciudad de Buenos Aires, para expresar sus "votos para que el encuentro entre Beguin y Sadat en Camp David resulte fructífero". La movilización, que recorrió las calles del barrio del Once, sería criticada por el director de la revista $L a$ Luz, Nissim Elnecave puesto que consideraba que "la política exterior de Israel no se puede decidir en una movilización callejera", menos aún cuando aquellos que se movilizaron "estaban siendo inconscientemente enarbolados por agitaciones tercermundistas que en última instancia pueden beneficiar a la extrema izquierda anti-israelí". ${ }^{24}$

Estas, de todas formas, no serían las únicas polémicas que alentarían las movilizaciones. Entre septiembre y octubre de 1978 el barrio de Flores, en la ciudad de Buenos Aires, sería testigo de un episodio particular. Frente a la decisión de las autoridades del Círculo Social Hebreo Argentino de habilitar el uso de sus instalaciones los días sábado, contrariando las reglas del campo religioso, un nutrido grupo de judíos ortodoxos se dirigieron al lugar y recriminaron la determinación. Finalmente, tras una nueva movilización el 14 de octubre, en la que los "manifestantes" rompieron varios vidrios del lugar, dando lugar a la intervención policial, varios religiosos fueron llevados presos, puestos a disposición de la justicia y liberados pocos días después. ${ }^{25}$

Las movilizaciones de los jóvenes y la confrontación entre judíos en las calles de Flores, serían indicativas de que la identificación y la actividad política no estuvieron vedadas ni parecen haber sido restringidas en el seno de la "comunidad judía" de Argentina. La O.S.A, por ejemplo,

20 "Inolvidable jornada vivió la comunidad", La Lu₹, 30 de marzo de 1979.

21 "Itzjak Rabín habla a la Argentina", Mundo Israelita, 9 de agosto de 1980. La actividad fue realizada el domingo 17 de agosto por la mañana. Pero, el viernes por la noche, en el Teatro SHA, Rabín brindó una conferencia que promovió la reacción de diversos grupos de religiosos "judíos" que denunciaron la "profanación del Shabat". Ver: "Honda repercusión tuvo en la colectividad la visita de Ytsjak Rabin", La Lu₹, 29 de agosto de 1981.

22 "Paz Ahora, también aquí, Nueva Presencia, 1 de septiembre de 1978.

23 Ver: "La paz en Israel y el agitacionismo tercermundista”, La Luz, 2 de junio de 1978; “Paz ahora? - ¿Paz segura?", La Luz, 30 de marzo de 1979. Según Elnecave la organización "Paz Ahora" es un movimiento antisionista y anti-israelí porque sus proclamas -las de construir un Estado Palestino en Israel- ponían en peligro la existencia del propio Estado israelí.

24 “La paz en Israel y...", op. cit.

25 "Enfrentamiento entre los sefaradim en Flores", La Luz, 3 de noviembre de 1978. Durante ese mismo año, según Susana Brauner, los grupos religiosos ortodoxos - como Jabad Lubavitch- comenzaron a celebrar las "festividades judías" con desfiles callejeros por la ciudad de Buenos Aires. Sobre los diversos segmentos del campo judío religiosoortodoxo durante la dictadura ver: Brauner, S., "En dictadura y democracia: 'argentinos', ultraortodoxos y banqueros", en Ortodoxia religiosa y pragmatismo político. Los judís de origen sirio., Buenos Aires, Lumiere, 2009. 
convocó a una "campaña de afiliación masiva" a pocos meses de haber ocurrido la toma del poder por parte de las Fuerzas Armadas. Y, según indican las convocatorias divulgadas en la prensa de la "comunidad judía", no se sugiere ningún tipo de medida de seguridad y/o resguardo para aquellos que quisieran afiliarse. ${ }^{26}$

Las disputas políticas y las contiendas electorales, a diferencia de lo que ocurría en el campo político nacional, provincial y/o local, no fueron cercenadas al interior de la "comunidad judía", ni estos las auto-suprimieron. A diferencia de lo que aconteció con partidos políticos y sindicatos, las instituciones judías no fueron intervenidas por el Poder Ejecutivo Nacional, ni los mandatos se prorrogaron automáticamente. En abril de 1976, mientras La Luz proclamaba que había que "erradicar a las lacras peronistas de la conducción judeo-argentina"27, Nehemías Resnizky volvía a ser elegido como presidente de la DAIA por los integrantes del plenario de la entidad. ${ }^{28}$ Durante su discurso de asunción, este aseveró que:

“[E]n el lapso de tiempo que ejerció su mandato la comisión directiva saliente, fue quizás el más difícil de la vida argentina después del fraticidio de 1820, y también fue especialmente difícil para la comunidad judía por la renovada agresión de la propaganda árabe y sus socios, tanto los antisemitas de siempre como la fementida izquierda antisionista. Entre estos márgenes tan difíciles y delicados podemos decir que la comunidad judía ha capeado el temporal, al menos al poder haber mantenido incólumes sus actividades educacionales, religiosas y comunitarias en medio de la tormenta". ${ }^{29}$

El reconocimiento de Resnizky en referencia al tercer gobierno peronista como la etapa "más difícil de la vida Argentina", agravada para la "comunidad judía", es ilustrativo de las representaciones de los actores en torno a cómo evaluaban el período inmediatamente anterior a la irrupción de las Fuerzas Militares el 24 de marzo de 1976. Pero, más sobresaliente para comprender cuáles eran los cánones para evaluar el buen desempeño de la entidad judía, resulta la afirmación realizada por Resnizky acerca de cómo debían ser considerados los objetivos de la DAIA para este período: haber sostenido el "normal" funcionamiento de la vida institucional de la "comunidad judía".

La evaluación en términos de "normalidad" institucional fue efectuada por los actores contemporáneamente al desarrollo de la vida "judía" durante la dictadura. Esta apreciación resulta relevante pues las críticas vertidas sobre la dirigencia comunitaria en torno de estas expresiones, sostuvo que la DAIA se vanaglorió de haber sostenido el "normal funcionamiento" de la vida institucional durante la transición democrática. Estas expresiones fueron impugnadas como una fórmula ex post de objetivos cumplidos por la entidad para salvaguardarse de las críticas de los familiares de afectados por las políticas represivas de la dictadura militar y los actores políticos "judíos" enfrentados con la conducción política de la "comunidad judía".

Pese a las críticas posteriores sobre quien fuera presidente de la DAIA, Nehemías Resnizky, este será nuevamente re-electo por los miembros de la Comisión Directiva de la DAIA en 1978. Durante su discurso sostuvo, como en la asunción de 1976, cuáles fueron los objetivos propuestos por la dirigencia de la DAIA en aquellos tiempos difíciles (1973-1978): "sostener el normal funcionamiento de la vida judía en el país, evitando el aislamiento al que quiere ser conducida la judeidad argentina por sectores hostiles, sin dejar de denunciar los ataques a la dignidad y el decoro de la vida judía en el país". ${ }^{30}$

26 "Con intensidad se desarrolla la campaña de afiliación", Mundo Israelita, 10 de julio de 1976.

${ }^{27}$ Elnecave, N., "Erradicar las lacras peronistas de la conducción judeo-argentina", La Luz, 9 de abril de 1976.

28 "La DAIA en estos años difíciles fue un medio decisivo para luchar por la dignidad judía", Mundo Israelita, 10 de abril de 1976; "El Dr. Nehemías Resnizky redesignado presidente de la DAIA”, La Lu₹, 9 de abril de 1976.

29 “El Dr. Nehemías Resnizky redesignado ...”, op. cit.

30 "Renuevan autoridades de la DAIA: el Dr. N. Resnizky reelecto presidente", Mundo Israelita, 1 de abril de 1978. 
Resnizky destacó como un logró que, frente a la prioridad que ha tenido para el Proceso de Reorganización Nacional la "lucha contra la subversión", la DAIA pudo preocupar a los funcionarios en torno del antisemitismo y la literatura nazi. ${ }^{31}$ Finalmente advirtió que por gestiones de la entidad que él conducía fueron obtenidos los permisos para que rabinos visiten presos políticos judíos. Sin embargo, aseguró que desde la dirigencia de la "comunidad judía" había un tema que los inquietaba: la arbitraria detención de Jacobo Timerman:

"Todavía no sabemos qué se le imputa y obviamente nos sometemos a las conclusiones que establezcan los tribunales de nuestro país. En numerosas oportunidades hemos expresado nuestra preocupación por su suerte, circunstancia que reiteramos hoy. Lo hacemos no sólo porque el tribunal que lo juzgó lo exoneró del cargo de subversión, sino porque Jacobo Timerman ha mantenido una constante y valiente lucha contra el antisemitismo y el nazismo identificándose plena y abiertamente con Israel y el movimiento sionista". 32

Como en 1976, en 1978 se destacaba la actuación de la dirigencia de la DAIA en procura de sostener el "normal" desenvolvimiento de la vida "judía" en Argentina, pero atendiendo a las nuevas problemáticas del período: la situación de los presos políticos "judíos” y la permanencia de Jacobo Timerman como detenido por el régimen. No obstante, como se sugiere en el discurso de Resnizky, ninguna de esas situaciones afectó el desenvolvimiento de los quehaceres institucionales. Incluso, al finalizar el mandato de Resnizky al frente de la DAIA, en 1981, sus gestiones fueron festejadas por quienes, pocos años después, serían sus detractores. En la efeméride celebratoria del final de la presidencia de Resnizky, el director del semanario Nueva Presencia, Herman Schiller, historizará el particular derrotero histórico nacional durante el cual el dirigente comandó los destinos de la entidad. Desde que este ingresó a los "cuerpos directivos" de la DAIA, se sucedieron ocho presidencias- Ongania, Levingston, Lanusse, Lastiri, Cámpora, Perón, Martínez de Perón y Videla- y no obstante los clivajes del derrotero político argentino, la evaluación editorial resultó satisfactoria:

"En suma: varios gobiernos (gorilas, ultraizquierdistas, peronistas, ultraderechistas) han pasado durante la gestión Resnizky y el equipo que lo acompañó. Sin embargo, la comunidad logró salir indemne (inclusive con dignidad) de todos los sacudimientos. [...] Su gestión- más allá de los discutibles "pragmatismos" que se adecuan naturalmente a las condiciones objetivas- es rescatable (hasta podría decirse que, en algún momento, fue marcadamente progresista, por lo menos en sus líneas generales) y sus contradicciones revelan la enorme dificultad que para el judaísmo de la diáspora supone tener que aunar su judeidad con la vasta gama de problemas que agitan al hombre contemporáneo". 33

La dinámica del "juego político" al interior de la propia DAIA pudo continuar pese a las restricciones imperantes en el espacio público nacional. Sin embargo, más significativas que las alternativas de la renovación de autoridades de la DAIA, resultan las posibilidades de realizar abiertas contiendas electorales en las organizaciones como la A.M.I.A y la O.S.A. Durante 1977 se realizó la convocatoria a renovar a los miembros de la Convención Territorial de la O.S.A y la elección de los delegados locales que participarían del Congreso de la Organización Sionista

\footnotetext{
${ }^{31}$ Durante los primeros años del régimen, a través de la intervención de la dirigencia de la DAIA, fueron cerradas dos editoriales que publicaban líbelos naizfascistas: Milicia y Odal. Para una análisis de las gestiones de la dirigencia judía frente al antisemitismo durante la dictadura militar ver: Kahan, Emmanuel, "Una temporada en el infierno": acerca de las respuestas producidas en torno del antisemitismo público y clandestino durante la última dictadura militar.", en Araucaria. Revista Iberoamericana de Filosofía, Historia y Humanidades No 29, Universidad de Sevilla, 2013. 32 "Renuevan autoridades de la DAIA...", op. cit.

33 Schiller, Herman, "Diez años volcánicos", Nueva Presencia, 20 de junio de 1980, pp. 1 y 3. Cabe destacar que en la editorial se menciona, por primera vez, las protestas de algunas madres de desaparecidos por la atención deficitaria que recibieron al concurrir a la DAIA. Asimismo, el editorialista señala que otras tantas voces señalan lo contrario.
} 
Mundial. Estas tuvieron lugar 27 de noviembre del mismo año y de la contienda participaron siete listas: Likud, Renovadores, Apartidarios, Mapam, Avodá, Sefaradim, Mizraji.

Previo al desarrollo del plebiscito tuvo lugar una Mesa Redonda de carácter pública en la sede el Centro de Educación Judía (Ayacucho $\mathrm{N}^{\circ}$ 632), organizada por la Nueva Presencia, el Club de Padres de Escuelas Hebreas (Horim) y la Confederación Juvenil Judeo Argentina, que contó con los candidatos de cada agrupación. ${ }^{34}$ A la misma, de acuerdo a la crónica de Nueva Presencia, concurrieron más de doscientas personas. ${ }^{35}$ Finalmente, durante el desarrollo de la contienda electoral, emitieron su voto 6.220 afilados a la OSA -sobre un total de 22.686 habilitados para votar- otorgando la victoria al partido oficialista "Avodá" con 1.813 votos.

Una situación similar tuvo lugar durante el mes de mayo de 1978: 7 listas participaron de las elecciones para renovar la mesa directiva de la AMIA. A diferencia de lo ocurrido el año anterior en las elecciones de la OSA, en esta oportunidad se produjeron alianzas y rupturas entre los partidos políticos comunitarios. "Fraie Schtime", por ejemplo, rompió con "Mapam" por su negativa a suscribir el programa sionista de esta última. En consecuencia, la agrupación sionistasocialista estrechó vínculos con el partido oficialista "Avodá". Asimismo, los ex-senadores radicales Zenón Goldstraj y José Jaritonsky, conformaron un grupo -el "Dash"- que compartió candidatos con el partido opositor "Jerut".

Finalmente, la elección se concretó con la emisión de alrededor de nueve mil votos, dos mil más que durante la última elección en 1974. La alianza triunfadora fue la que componían "AvodáMapam" que contó con el apoyo de 4.019 votos, el 45\% de los sufragios emitidos. ${ }^{38}$ Según la crónica de Nueva Presencia, el triunfo de "Avodá-Mapam" iba en contra de lo que ocurría en el campo político "judío” en Israel y la diáspora:

"[A] diferencia de lo que pasa en Israel y el resto de la comunidades del mundo, donde se registra un vuelco hacia el Likud, en Argentina Avodá arrolló a sus opositores con el 45\% de los votos. [... [ [S] u triunfo no se debió solo al 'aparato' movilizado, sino que los votantes fueron movilizados por la vocación laicista-progresista -contra los sectores religiosos-: o sea, votaron aquellos sectores ideologizados contra el único sector que podía frenar el avance de las tendencias regresivas". ${ }^{39}$

Como pudo observarse, la movilización, participación y los debates políticos sobre la conducción de las instituciones centrales de la "comunidad judía" no sufrieron interrupciones durante el período dictatorial. ${ }^{40}$ Incluso el ICUF- que no participaba de la puja por la distribución del poder

34 “El sionismo argentino, hoy", Nueva Presencia, 19 de noviembre de 1977.

35 "OSA: elecciones e incógnitas", Nueva Presencia, 26 de noviembre de 1977.

36 “OSA: elecciones...", op. cit.; "Deparó sorpresas el comicio sionista”, La Lu₹, 1 de enero de 1978. El análisis de Nueva Presencia destaca un tópico que es significativo: las últimas elecciones en la OSA tuvieron lugar durante el año 1971, no pudiéndose concretar el correspondiente comicio durante el gobierno democrático peronista. En esa última elección, la de 1971, sólo participaron 2.597 personas. Ver: "Ajustada victoria de Avodá”, Nueva Presencia, 3 de diciembre de 1977.

37 "Comicios a la vista", Nueva Presencia, 24 de abril de 1978.

38 Inobjetable triunfo de Avodá en la elecciones de AMIA", La Lu₹, 2 de junio de 1978; "El frente comunitario de Avodá afirmó su posición mayoritaria en los comicios", Mundo Israelita, 27 de mayo de 1978.

El resultado de los comicios efectuados en 1978 abrieron la puerta aun debate que, iniciado en las páginas de Mundo Israelita, no tuvo una recepción y/o continuidad en las páginas de la prensa "judía” pero que planteo un problema que, hasta el momento, había permanecido silenciado: la ausencia de las mujeres en los puestos de conducción "comunitaria". Ver: "La mujer ausente", Mundo Israelita, 30 de diciembre de 1978.

39 "Lecciones de una elección”, Nueva Presencia, 27 de mayo de 1978.

${ }^{40}$ En una oportunidad los diversos dirigentes de las instituciones judías resolvieron no convocar a elecciones para la renovación de autoridades. Fue en 1981 cuando se acordó una lista única para la renovación de la mesa directiva de la A.M.I.A. No motivó la iniciativa la aceptación de la veda política sino la profunda crisis económica por la que atravesaban las instituciones de la "comunidad judía" a raíz de la espiral inflacionaria que caracterizó al período. Ver: "El momento que vivimos justifica una lista unificada para la AMIA", Mundo Israelita, 16 de mayo de 1981. 
en estas instituciones- pudo convocar en 1976 y 1980 a los XI ${ }^{\circ}$ y XII “Congresos del ICUF" en los que se discutió la plataforma política de las entidades asociadas. ${ }^{41} \mathrm{Y}$, en 1981, realizó las "Icufiadas 81 ", de la que participaron más de 700 jóvenes que se "pronunciaron sobre temas que conmueven actualmente a la juventud y la ciudadanía argentina". Por ejemplo, en la mesa "socio-política" participaron miembros del ICUF, voceros de la Juventud Radical y un miembro del Consejo Argentino de la Paz. ${ }^{42}$

Si bien estos eventos no cuestionaron los objetivos del régimen dictatorial, permiten poner en suspenso la representación acerca del cierre del espacio público en tiempos dictatoriales tal como fuera planteado por Novaro y Palermo. Las actividades desplegadas, así como los debates y las movilizaciones de los diversos actores de la "comunidad judía" permiten observar una dinámica que no sólo no fue clausurada durante la dictadura militar sino que, en contraste con el período inmediatamente anterior, pudo desarrollarse activamente.

\section{“¿Quién resistirá cuando el arte ataque?”: las grietas en el discurso cultural del régimen}

"El sexo va a la escuela" fue el título de tapa del primer ejemplar de la revista Plural, de la Sociedad Hebraica Argentina, publicado en agosto de $1976 .{ }^{43}$ Contra la dimensión cultural que la dictadura militar pretendía sostener en pos de reordenar a la sociedad civil, la iniciativa de la SHA comenzaba por socavar los valores culturales que el régimen impulsaba. Si bien la bibliografía se ha concentrado en la renovación que significó en el mundo editorial, en tiempos de la dictadura, la Revista $H u m o{ }^{\circledR}{ }^{44}$, y el "refugio" que significó para muchos intelectuales la aparición de Punto de Vista, Plural-obviamente, una experiencia de circulación reducida al ámbito de una institución de la "comunidad judía" - puso en circulación una serie de debates sobre aspectos que en el espacio público estaban vedados según la bibliografía sobre el oprobio cultural que significó la dictadura. ${ }^{45}$

Dirigida por Alberto Sendery, bajo la asesoría de Mario Diament y la jefatura de redacción a cargo de Alicia Dujovne Ortiz, Plural contó con una larga lista de colaboradores: Miguel Grinberg, Daniel Muchnik, José Ignacio López, Martín Müller, Mario Satz, Ernesto Schoo, Tamara Kamenszain y Fernando del Corro, entre otros. En su primer número, además del artículo sobre el "sexo en la escuela", se encuentra una de las primeros trabajos que Miguel Grinberg escribiría sobre los jóvenes, el rock y sus experiencias culturales. ${ }^{46}$ Incluso, en un ejemplar posterior, el rock ocupará un lugar central: "Del mesías y del Rock" será el trabajo de Grinberg que ilustrará la tapa del segundo número de revista de Hebraica. ${ }^{47}$

El lugar otorgado a las expresiones artísticas y los consumos culturales de los jóvenes ocuparía uno de los lugares destacados de la revista de la SHA. Incluso, en sintonía con el acomodamiento de los jóvenes sionistas frente a las nuevas circunstancias que imponía el régimen dictatorial, el lugar otorgado a la juventud en Plural será ilustrativo de los espacios que se abrían en el seno de la "comunidad judía" para dar "refugio" a los jóvenes frente a un ámbito externo que se presentaba como "peligroso" o "prohibido". La entrevista a los jóvenes del Club Atlético Sefaradí Argentino

\footnotetext{
41 “Llamamiento del XI Congreso del ICUF”, Tiempo, № 95, octubre de 1976; “Al congreso del ICUF, salud!", Tiempo $\mathrm{N}^{\circ} 140$, octubre de 1980.

42 "Icufiada 81", Tiempo, N 149, agosto de 1981.

${ }^{43}$ Kamneszain, T., "El sexo va a la escuela. Informe especial”, Plural $\mathrm{N}^{\circ} 1$, agosto de 1976.

${ }^{44}$ Ver Burkart, M., HUMO(R): El surgimiento de un espacio crítico bajo la dictadura militar, 1978-1979, Tesis de Maestría en Sociología de la Cultura y Análisis Cultural, IDAES-UNSAM, 2008. (Inédita)

45 Invernizzi, H. y Gociol, J., Un golpe a los libros. Represión a la cultura durante la última dictadura militar, Buenos Aires, Eudeba, 2003.

${ }^{46}$ Grinberg, M., "La nueva música argentina”, Plural $\mathrm{N}^{\circ}$ 1, agosto de 1976. Resulta relevante destacar, como sugiere Sergio Pujol, que los primeros años del régimen dictatorial también fueron persecutorios al interior de este ámbito musical; ver Pujol, Sergio, Rock y dictadura., Buenos Aires, Emecé, 2006.

${ }^{47}$ Grinberg, M., "Del Mesías y del Rock", Plural N 3, octubre de 1976.
} 
resulta ilustrativa del incremento de las actividades en relación proporcional a la afluencia cada vez mayor de asistentes a las actividades: la Secretaría de Edad Universitaria, por ejemplo, destaca que las charlas de "educación sexual" obtuvieron un "éxito rotundo" con la asistencia de 50 personas. $^{48}$

Así como las referencias a los jóvenes podían estar asociadas al sexo o al rock, también aludían al "retorno" de la espiritualidad. Alicia Dujovne Ortíz indagaría en otros espacios que fueron considerados de "retorno" para los jóvenes, donde se garantizaba su seguridad. ${ }^{49}$ Las entrevistas realizadas a tres exponentes de diversas corrientes del espectro religioso de los "judíos"- rabino Roberto Graetz (reformista, Templo Emanu-El), rabino Marshall Meyer (conservador, Templo Bet-El) y doctor José Oppenheimer (ortodoxo, Congregación Concordia Israelita)- coinciden en caracterizar a los jóvenes de una forma despolitizada, señalando que había un "acercamiento" a la religión.

Porque si bien se podían abordar temas transgresores, la "política" no era un tópico de las reflexiones editoriales del mensuario. Incluso cuando algunas de las editoriales aludían a la coyuntura política, las referencias eran de apoyo y aceptación de los objetivos del Proceso de Reorganización Nacional. ${ }^{50}$ No obstante, desde el primer número, los análisis efectuados por Daniel Muchnik sobre el programa económico implantado por la dictadura militar- como luego lo hará desde Nueva Presencia- se convirtieron en una constante crítica al equipo liderado por Martínez de Hoz. ${ }^{51}$ Sin embargo, la reprobación del programa económico de la dictadura no se trató de un tópico original de Plural: desde la columna "Tiempo Argentino" -en el mensuario icufista Tiempo- Grisha Weltman y Eduardo Vaiser condenaron tempranamente la impronta desindustralizadora del modelo económico dictatorial. ${ }^{52}$

No obstante, la diversidad temática de Plural como más adelante pasará con Nueva Presencia -un caso similar aunque de mucha mayor trascendencia pública- así como la posibilidad de abordar temas que a los ojos de los "censores" del régimen podrían aparecer problemáticos y/o transgresores, permite mostrar que al interior de la "comunidad judía" se registraron grietas frente al impacto de la censura cultural promovida por el régimen dictatorial. Además de las notas sobre el sexo y el rock, Tamara Kamenszain recupera en una extensa reseña las "revistas literarias" que fueron censuradas por la dictadura militar. ${ }^{53}$

\footnotetext{
48 “Hablan los jóvenes de C.A.S.A.”, Plural N 3, Octubre de 1976.

49 Dujovne Ortiz, A., "La juventud y el templo", Plural $\mathrm{N}^{\circ} 1$, agosto de 1976. Sobre el crecimiento y expansión de la corriente religiosa de los judíos conservadores - asociados a la figura del rabino Marshal Meyer y el Seminario Rabínico Latinoamericano-, véase Schenquer, L., “(Re)ligión, política y 'comunidad' judía: representaciones e imaginarios sociales en el contexto de la dictadura argentina”, en Kahan, E., Schenquer, L., Dujovne, A. y Setton, D., Marginados y consagrados. Nuevos estudios sobre la vida judía en Argentina. Buenos Aires, Lumiere, 2011.

${ }^{50}$ Véase Peredes, E., "Reforma o Decadencia?, Plural N 1, agosto de 1976; López, J. I., "Indicios de renovación", Plural $\mathrm{N}^{\circ}$ 3, octubre de 1976.

51 Véase Muchnik, D., "Las metas del desarrollo", Plural N 1, agosto de 1976; “Al final se verá quién tuvo razón”, Plural N 3, octubre de 1976; "Las teorías esotéricas en economía”, Plural No 4, noviembre de 1976; "Los ejecutivos, ique vivos que son!”, Plural $\mathrm{N}^{\circ}$ 5, enero de 1977.

${ }^{2} \mathrm{Ni}$ siquiera se trató de una perspectiva original en estas dos publicaciones. Como señala el trabajo de Borrelli sobre el diario Clarín, la crítica al programa económico de Martínez de Hoz fue contemporánea a su implementación. Véase Borrelli, M., "El diario Clarín y la participación civil en los primeros años de la dictadura (1976-1978): gobernar con los 'mejores hombres', pero sin la 'partidocracia", ponencia presentada en $\mathrm{V}^{\circ}$ Jornadas de Trabajo sobre Historia Reciente, Universidad Nacional de General Sarmiento, 2010.

Lo que si es relevante para el análisis de nuestro caso, es la figura de Daniel Muchnik, quien fue el jefe de redacción de la sección "Economía" de Clarín durante la primera parte del período dictatorial y que escribiría en Plural y luego en Nueva Presencia. Durante la entrevista realizada a Muchnik, él señaló que la diferencia entre las notas publicadas en Clarín y lo que podía escribir en las medios gráficos de la "comunidad judía", radicaban en la forma y la extensión: mientras que en Clarín debía asumir un carácter más profesional -atendiendo a qué decía y cómo- las páginas de Plural y Nueva Presencia le permitían expresarse sin inhibiciones (Entrevista realizada por el investigador).

53 "Vida, pasión y muerte de las revistas literarias", Plural N 16, junio de 1978.
} 
En este sentido, como en el caso del desarrollo de la actividad política en el seno de la "comunidad judía", se puede proponer que en el campo cultural los márgenes se ampliaron en relación a lo que sucedía en el resto de la sociedad civil. ${ }^{54}$ Desde las páginas de Plural y Nueva Presencia son recurrentes las críticas a la censura cultural impuestas por la dictadura militar calificándolas de absurdas, arbitrarias y pacatas. ${ }^{55}$

Sin embargo, esa amplitud de los márgenes para desarrollar distintas empresas culturales no significa sostener que los actores desconocían la potencial peligrosidad del régimen. En una efeméride sobre el día del periodista, escrita por Daniel Muchnik en 1980, se señala que la prensa en la "hora actual" estaba "adormilada, apoltronada, alicaída":

"Es que en Argentina sucedieron cosas graves. (...) Pero todo aquello fue un juego de niños al lado del Lopezrreguismo y las patrañas sangrientas desatadas por la ultraderecha y la ultraizquierda. Corrió sangre. El miedo, un tremendo y lacerante miedo se adueñó de los ánimos y los espíritus creativos de algunos periodistas".

Por esta razón es que otros actores de la "comunidad judía" debieron redefinir sus propuestas para el desarrollo de diversas actividades culturales. En diciembre de 1976, Marcos Aguinis remitió una carta a las autoridades del Congreso Judío Mundial para informarlos sobre cómo resultó la organización del "Primer Coloquio Latinoamericano sobre Pluralismo Cultural". En la misma, señaló cuáles fueron los problemas que él, en su carácter de coordinador de la actividad, debió solucionar.

En primer término, como se pensó que el evento podía peligrar, se buscó para el desarrollo de las sesiones un "ámbito oficial", asegurar la asistencia de funcionarios públicos y, para darle un tono más afín a los valores culturales sostenidos por el régimen dictatorial, re-nombrar el evento. El Coloquio sobre "Pluralismo Cultural e Integración Nacional" tuvo lugar en el Centro Cultural General San Martín y contó con la presencia del Director General de Educación de la ciudad de Buenos Aires, Dr. Enrique Belloc, quien hablaría en nombre de las autoridades municipales y nacionales.

Pero, aún con estas adaptaciones, señala Aguinis, los organizadores debieron enfrentar un problema aún mayor: decidir quiénes serían los conferencistas. La convocatoria a los participantes intentó cubrir un amplio abanico de personalidades, "evitando todas aquellas personas que pudieran suscitar algún tipo de irritación". Según Aguinis, gracias a "su condición de escritor y sus vínculos con el quehacer cultural latinoamericano", así como con la obtención de una "sede oficial" para el evento, los relatores convocados fueron aceptando la invitación: Monseñor Antonio Quarracino (presidente del Secretariado General del Ecumenismo), Obispo Sante Uberto Barbieri (ex presidente del Consejo Mundial de Iglesias), la escritora Syria Poletti, Dra. Susana Chertudi (Jefa del Instituto Nacional de Antropología), Jochen Bloss (Director

\footnotetext{
54 Incluso, para sugerir futuras perspectivas de investigación, se puede proponer que habría que poner en suspenso cierta representación cristalizada en el sentido común respecto de la eficacia de la censura cultural impuesta por la dictadura militar. Las columnas sobre crítica cultural realizadas por Graciela Safranchik en Nueva Presencia, por ejemplo, muestran un amplio abanico de representaciones teatrales y puestas cinematográficas que no sólo no fueron censuradas, sino que expusieron obras de autores prohibidos: Bertolt Brecht, Germán Rozenmacher, etc.

${ }^{55}$ En la viñeta de un artículo de Luis Gregorich, publicado originalmente en la revista Medios y Comunicaciones, se crítica que "mientras la pornografía reprimida de las películas en las que interviene la dupla Olmedo-Porcel circula sin problemas de censura, la miniserie televisiva Holocausto no puede ser apreciada por el público argentino". Véase Gregorich, L., "Una censura que fomenta la obscenidad", Nueva Presencia, 30 de noviembre de 1979 (el artículo luego

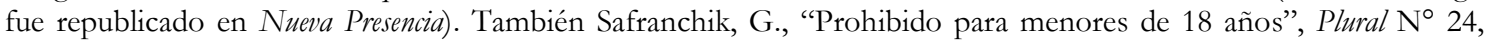
julio de 1980.

${ }^{56}$ Muchnik, D., "Sin coraje y sin riesgos no hay periodismo auténtico", Nueva Presencia, 13 de junio de 1980.
} 
Instituto Goethe) y Gregorio Weinberg (ex-Director del Centro Internacional de Documentación de la UNESCO)..$^{57}$

El éxito del evento, al que concurrió un nutrido público y reconocidas personalidades que oficiaron de conferencistas, motivo la realización de otro similar en diciembre de 1978. El Centro Cultural General San Martín, como en la primera oportunidad, sería el "ámbito oficial” para el desarrollo del "Segundo Coloquio sobre Pluralismo Cultural". En esta oportunidad participarán reconocidos académicos como Gregorio Klimovsky, Eugenio Pucciarelli, Ester Hermitte, José Luis de Imaz, Leonardo Senkman, Natalio Botana, Ezequiel Gallo, Roberto Cortés Conde. ${ }^{58}$

Otro de los aspectos que se pueden destacar, a partir de las experiencias de los coloquios de "Pluralismo Cultural", es que las actividades desarrolladas por diversos actores de la "comunidad judía" no se limitaron a ser desarrolladas en el espacio público "comunitario". La posibilidad de acceder a "ámbitos oficiales", como el centro Cultural General San Martín, y a salas de cines de acceso público, como el Majestic y el Metro, permiten proponer que las actividades desplegadas por las organizaciones de la "comunidad judía" no sufrieron ninguna restricción en el espacio público. Incluso, la celebración del $28^{\circ}$ aniversario de la creación del Estado de Israel tuvo una velada de gala en el Teatro Colón a la que asistieron dirigentes, autoridades estatales, diplomáticos, artistas y científicos, entre otros. ${ }^{59}$

Sin embargo, la realización de ambos Coloquios, según describe Marcos Aguinis, permiten reconocer el despliegue de estrategias fundadas en el reconocimiento de la política de persecución perpetrada por el régimen dictatorial. En este sentido, la ponderación del abierto espacio público en los marcos de la "comunidad judía" -tesis central de este trabajo- también debe matizarse teniendo en consideración el propio reconocimiento de los actores sobre los alcances de la política represiva.

A su vez, el relevamiento documental permite proponer una hipótesis aún más polémica: el desarrollo de ciertas actividades bajo los marcos de las instituciones "judías" brindaron un hálito de seguridad e, incluso, de libertad a individuos que corrían riesgos al hacer esas mismas actividades en otros ámbitos. Liliana Hecker señala, en una entrevista realizada por María Matilde Ollier, que durante la dictadura empezó a dar talleres literarios en el Teatro IFT, "que era de izquierda":

"Era impresionante la cantidad de gente que venía y ahí surgen los talleres como fenómeno, porque en la dictadura funcionan como pequeños ámbitos de libertad donde se podía leer y, por ejemplo, se podía hablar de Freud, que afuera estaba prohibido". ${ }^{60}$

El Teatro IFT, ubicado en el barrio del Once, no sólo era de izquierda, sino que pertenecía al ICUF: el Idisher Folks Theater (Teatro Popular Judío) era un teatro de izquierda perteneciente a la "comunidad judía". Como en el caso de Hecker, el análisis del material documental nos permitirá encontrarnos con diversas voces que, provenientes de la universidad, el periodismo, la economía

57 Carta de Marcos Aguinis a autoridades del Congreso Judío Mundial sobre realización de "Primer Coloquio Latinoamericano sobre Pluralismo Cultural", 7 de diciembre de 1976. Archivo Resnizky (CES-DAIA). Según la crónica de Mundo Israelita las personalidades que oficiaron de conferencistas fueron Eugenio Pucciarelli (Academia Nacional de Cencias), Norberto Rodríguez Bustamante, Jaime Barylko, Reverendo Padre Boris Gabriel Turel, Hebe Clementi, Egron Schaden, Adolfo Silva Delgado, Paul Warzawsky, Narciso Binayán, Miguel Wasylik y el rabino Marcos Edery, entre otros. Véase "Se inicia una experiencia inusual: El Primer Coloquio Latinoamericano sobre Pluralismo Cultural", Mundo Israelita, 20 de noviembre de 1976.

58 "Se inicia el coloquio sobre pluralismo cultural", Nueva Presencia, 1 de diciembre de 1978.

59 "La conmemoración en el Colón. Saliendo de los marcos rutinarios", Mundo Israelita, 8 de mayo de 1976. Incluso se señala que, la "comunidad" pudo salir de "los marcos rutinarios" y festejarlo en un ámbito distinto al del espacio público "comunitario".

${ }^{60}$ Ollier, M. M., De la Revolución Argentina a la democracia. Cambios privados, públicos y politicos de la izquierda argentina., Buenos Aires, Siglo Veintiuno, 2009, p. 109. 
y la política, encontraron un ámbito para "hablar", pero también un auditorio que estuviera dispuesto a escucharlos.

Al interior del espacio público "comunitario" tuvieron lugar iniciativas que, además de resultar convocantes, permitieron que diversos profesionales pudieran dar cursos y/o dirigir espacios de formación intelectual. En abril de 1976 tendrán lugar dos iniciativas significativas: el Instituto de Estudios Superiores de Hebraica (IDES-Hebraica) y el Centro de Estudios Judío (CEJ). La primera de ellas contó con la coordinación de José Luis Romero ${ }^{61}$ y la presencia en su plantel docente de Luis Alberto Romero, quien dictaría el curso sobre "El 80: proyecto y desarrollo de la Argentina liberal". ${ }^{2}$

El CEJ contaba con el auspicio de la Agencia Judía ${ }^{63}$ y estaba asesorado académicamente por la Universidad de Tel Aviv. Su objetivo, de acuerdo al testimonio de uno de sus primeros coordinadores, era brindar formación a futuros "líderes comunitarios". ${ }^{64}$ Tras la primera convocatoria a inscripciones, aparecida en Mundo Israelita y La Luz durante la primera semana de mayo de 1976, se recibieron más inscripciones que las esperadas: de 138 aspirantes, sólo podrían asistir a los cursos 85 personas. ${ }^{65}$ Las asignaturas y docentes del curso fueron las siguientes: 1) "Pensamiento judío contemporáneo", a cargo del rabino Roberto Graetz y Mario Albin, 2) "Historia social del judaísmo argentino", dictada por Julio Brenner, 3) "Raíces históricas del conflicto árabe-israelí", dado por Yaacov Rubel y 4) "Identidad judía, laboratorio de reflexión grupal", coordinado por Luis Sidicaro y Eduardo Rogoski. ${ }^{66}$

Pero, además de estos espacios, existieron otros menos estructurados en los cuales brindaron conferencias distinguidas personalidades de diversos ámbitos de la producción cultural, científica, intelectual, literaria y periodística, entre otras: "los miércoles de la Sociedad Hebraica Argentina" y "los Jueves de Hacoaj". Por allí pasaron Ernesto Sábato ${ }^{67}$, Jorge Luis Borges ${ }^{68}$, Gregorio Klimovsky, Bernardo Korenblit, Juan Carlos Ghiano ${ }^{69}$, Cesar Tiempo, Berta Singerman, León Dujovne, Roberto Tálice, Juan José Jusid ${ }^{70}$, Julio César Calvo, Silvio Huberman, Enrique Pugliese, Daniel Muchnik, Alberto Rudni, Ernesto Schoo ${ }^{71}$, Pacho O’Donnell, Luis Gusman, Enrique Medina, Rodolfo Rabanal, Manuel Mújica Láinez ${ }^{72}$, Carlos Carballo, Roberto Lavagna ${ }^{73}$ y Carlos Fayt ${ }^{74}$, entre muchos otros.

Pero un tópico más debe ser destacado en post de complejizar el análisis: la cuantiosa y diversa gama de conferencias y cursos tenían lugar en horarios nocturnos, comenzando entre las 20:30 hs. y las 21:00 hs. ¿Y el estado de sitio? ¿Y el temor a transitar por la vía pública a la noche?

\footnotetext{
61 "SHA inicia el ciclo de miércoles culturales", Mundo Israelita, 24 de abril de 1976.

62 "Publicidad IDES Hebraica", Mundo Israelita, 2 de agosto de 1980. Entre los otros cursos que se dictaban, se encontraron: "La concepción judía del hombre" a cargo del Prof. Mordejai Levin, "Posiciones árabes y judías y su incidencia en el desarrollo del conflicto en Medio Oriente" dado por Shimón Farja y, finalmente, "Crisis y pensamiento contemporáneo", brindado por el Prof. Abraham Haber.

${ }^{63}$ Un organismo encargado de la gestión de la inmigración judía hacia Israel.

${ }^{64}$ Entrevista a Yaacov Rubel realizada por el investigador.

65 "Alto nivel del Centro de Estudios Judíos", La Luz, 21 de mayo de 1976.

66 "Se iniciaron los cursos del CEJ", Mundo Israelita, 15 de mayo de 1976.

67 "Jueves de Hacoaj", Mundo Israelita, 5 de abril de 1980.

68 "Homenaje a Spinoza en Hebraica", Mundo Israelita, 9 de julio de 1977. En la misma mesa participaron Bernardo Korenblit, Gregorio Wainberg, Jaime Barylko, Padre Carlos Cucheti y Luis Farré.

69 "Miércoles de SHA", Mundo Israelita, 24 de abril de 1977.

70 "Jueves de Hacoaj: homenaje a Alberto Gerchunoff", Mundo Israelita, 2 de septiembre de 1978.

71 “Jueves de Hacoaj: Nosotros, los periodistas", Mundo Israelita, 12 de julio de 1980.

${ }_{72}$ Publicidad de actividades en el SHA y Hacoaj, Mundo Israelita, 4 de octubre de 1980.

73 “Jueves de Hacoaj: Encrucijada económica 1981", Mundo Israelita, 23 de marzo de 1981.

74 “Octubre en el SHA", La Lu₹, 22 de septiembre de 1978.
} 
Durante las entrevistas realizadas a quienes fueron partícipes de estas experiencias -Yaacov Rubel y Juan Gurevich ${ }^{75}$ - las respuestas resultaron precisas: "No teníamos miedo".

La negación del temor frente a esta pregunta contrastó con los relatos que aludían a la política represiva del régimen. Los entrevistados, cuando eran interpelados en torno a las acciones desplegadas frente a la política represiva de la dictadura militar, referían la imposibilidad o los estrechos márgenes para actuar -por ejemplo, para solicitar averiguaciones en torno a la desaparición forzada de algún individuo denunciado en las instituciones centrales de la "comunidad judía"-. ${ }^{76}$

¿Cómo descifrar estas experiencias diferenciadas y contemporáneas frente al temor? Pues, efectivamente, según el registro documental, las actividades nocturnas, al menos al interior de la "comunidad judía", no cesaron. Incluso, se incrementaron en número y en cantidad de asistentes en relación al período anterior. Pareciera que se estuviera frente a la co-existencia de dos sensaciones simultáneas: el temor frente a la "participación" y/o "expresión" "política" y la "seguridad" de transitar una cotidianeidad nuevamente re-ordenada como producto y/o consecuencia de la propia política represiva que causaba el temor en la primera instancia.

En este sentido, de acuerdo a la investigación realizada por Adrián Jmelnizky, la "comunidad judía" durante los "años de plomo" fue percibida como un lugar seguro: frente al "afuera" que era peligroso y amenazante, el "adentro" constituyó un espacio protegido. Según el investigador, esto explicaría por qué los proyectos se multiplicaron y los espacios "comunitarios" crecieron tanto en inclusión como en participación. ${ }^{77}$ Así como tuvieron lugar el CEJ, IDES-Hebraica, los "miércoles de SHA" y los "jueves de Hacoaj", proliferaron ámbitos de congregación y reuniones para los jóvenes. Asimismo, al igual que en el Teatro IFT, donde se exhibieron obras de Bertold Brecht, la cinemateca de la Sociedad Hebraica Argentina proyectó ante una nutrida concurrencia una serie de films que no se encontraban en las salas comerciales.

\section{Algunas consideraciones}

El amplio espectro de actividades relevadas permite poner en tensión o al menos interrogarnos acerca de cómo se desarrolló la "vida pública comunitaria" en un contexto caracterizado por el estado de sitio. Entre las primeras medidas sancionadas por la Junta Militar, la dictadura impuso una fuerte restricción al desarrollo de actividades públicas y al derecho de reunión. Sin embargo, como muestra el trabajo de Miranda Lida al analizar las movilizaciones al interior de los movimientos católicos ${ }^{78}$, el registro pormenorizado del desarrollo de diversas actividades por distintos actores de la sociedad civil permitiría poner en suspenso ciertas nociones acerca de la restricción del espacio público en el contexto dictatorial.

Las investigaciones sobre el desarrollo actividades "políticas", "culturales" y "sociales" en contextos dictatoriales, deberían tener en cuenta la hipótesis sostenida por Luis Alberto Romero en torno de los sectores populares durante la dictadura inaugurada por José Felix Uriburu. Pues si bien allí también fueron cercenadas las formas de participación política consagrada a los partidos políticos, "los sectores populares se replegaron en los ámbitos celulares de la sociedad, en una

\footnotetext{
75 Entrevistas realizadas por el investigador. Pregunté a ellos por la experiencia del CEJ y las conferencias, ya que uno, Rubel, había sido coordinador del CEJ y el otro, Gurevich, un alto dirigente de la DAIA que concurría a muchas de las actividades convocadas.

${ }^{76}$ Kahan, Emmanuel, "Una temporada en el infierno:...", op. cit.

77 Jmelnizky, A., "Aproximación a los últimos treinta años de trabajo comunitario con jóvenes judíos en edad universitaria”, en Zelcer, B., y Trajtenberg, G., Los adultos jóvenes judíos, Buenos Aires, Agencia Judía para Israel, 2003, pp. 77-95.

${ }_{78}^{7}$ Lida, Miranda, "Movilizaciones católicas en tiempos de represión militar y dictadura. Sociedad, régimen militar e Iglesia Católica en Argentina, 1976-1982”, en www.historiapolitica.com
} 
serie de organizaciones que se desarrollaron en los barrios y en las cuales era posible mantener una cierta experiencia de participación igualitaria". ${ }^{79}$

En este sentido, el presente trabajo sobre el despliegue de actividades al interior de la "comunidad judía" permite considerar que en contraposición con lo sucedido en el espacio público "nacional", las prácticas en ámbitos "comunitarios" tuvo un amplio margen para su desarrollo. Esta observación, a su vez, permitiría matizar las narrativas tendientes a caracterizar a la política oficial de la dictadura como persecutoria de la "vida judía" en Argentina. Si bien la bibliografía sobre los "judíos" durante la dictadura ha destacado el carácter antisemita del régimen dictatorial, la amplia gama de actividades públicas, así como el desarrollo sin restricciones de la "vida política" al interior de la "comunidad judía", permite matizar el juicio sobre el carácter oprobioso de la vida cotidiana para los "judíos" y/o sus instituciones durante la dictadura militar.

Esta afirmación, no obstante, debe ser matizada teniendo en cuenta el temprano impacto que las denuncias sobre antisemitismo del régimen dictatorial tuvieron en el escenario internacional. Un informe policial de la Dirección de Inteligencia de la Policía de la Provincia de Buenos Aires (DIPBA), iniciado tras la "profanación de un cementerio judío" en Ciudadela durante el mes de octubre de 1980, advierte al agente policial que lleva adelante la investigación: "¡Investigar! Hecho grave que puede tener repercusiones internacionales" ${ }^{80}$ La materialización del temor acerca de las repercusiones que podría adquirir la dimensión transnacional de lo que acontecía con el funcionamiento de la red institucional judía en Argentina puede ser explicativa de la atención y/o circunstancial eficacia de las demandas realizadas por la dirigencia de la "comunidad judía".

Si bien el régimen dictatorial se caracterizó por la persecución, detención y posterior desaparición de individuos, las investigaciones no pueden desdeñar que la vida cotidiana continuó desarrollándose aún bajo el signo de la política represiva. Incluso, para poder comprender cómo fue posible que algunos actores pudieran enunciar - pese al dolor que esta afirmación produjera a los afectados por el terrorismo de Estado- que la "comunidad judía" "ffloreció" y funcionó "normalmente", deberá considerarse cuál fue la experiencia que estos mismos actores atravesaron durante el período inmediatamente anterior a la dictadura militar.

En este sentido, el registro de un aumento considerable de actividades y asistentes permitiría comprender la definición a la que recurrieron los actores para describir el desarrollo de la vida judía en el contexto dictatorial: "normalidad" y "florecimiento". El relevamiento de actividades desarrolladas, por ejemplo, en el campo cultural permiten considerar que no sólo los individuos adscriptos a las instituciones de la "comunidad judía" gozaron de un "lugar seguro", como sostiene la tesis de Jmelnizky. La asistencia, ya sea en calidad de conferencistas y como docentes, registró la participación de destacadas personalidades "no-judías" que, incluso, tenían vedado el auditorio en el espacio público "nacional".

\footnotetext{
${ }^{79}$ Romero, Luis Alberto, “Participación política y democracia, 1880-1984”, en Romero, Luis Alberto y Gutiérrez, Leandro, Sectores populares, cultura y política., Buenos Aires, Sudamericana, 1995, p. 120.

${ }^{80}$ Legajo N ${ }^{\circ}$ 17.448, Mesa "DS" [Delincuente Subversivo], Carpeta Varios, Carátula: Atentado Cementerio Israelita (Ciudadela)", Archivo DIPBA.
} 